\title{
Penerapan Data Mining Untuk Memprediksi Pemesanan Bibit Pohon Dengan Regresi Linear Berganda
}

\author{
Devi Sari Oktavia Panggabean, Efori Buulolo, Natalia Silalahi \\ Program Studi Teknik Informatika, STMIK Budi Darma, Medan, Indonesia \\ Email: ${ }^{1}$ devisarioktaviapanggabean @gmail.com
}

Submitted 13-01-2020; Accepted 03-02-2020; Published 15-02-2020

\begin{abstract}
Abstrak
Data mining, sering juga disebut knowledge discovery in database (KDD), adalah kegiatan yang meliputi pengumpulan, pemakaian data historis untuk menemukan keteraturan, pola atau hubungan dalam set data berukuran besar. Keluaran dari data mining bisa dipakai untuk memperbaikin pengambilan keputusan dimasa depan. Masalah yang sering terjadi pada BPDASHL adalah masalah estimasi seperti cuaca, kesulitan dalam penanaman, kurangnya tenaga kerja, kurang pengalaman dalam pembibitan pohon, serta kondisi tanah yang berbeda-beda. Masalah lain yang terdapat dalam instansi yaitu belum mempunyai sistem untuk memprediksi estimasi pemesanan bibit pohon setiap tahunnya sehingga diperlukan suatu metode yaitu Algoritma Regresi Linear Berganda. Maka dengan ini dibuatlah Penerapan Data Mining Untuk Memprediksi Pemesanan Bibit Pohon Dengan Regresi Linear Berganda. Algoritma Regresi Linear Berganda yang merupakan metode yang mendukung dalam memperkirakan atau memprediksi target pemesanan untuk periode yang akan datang. Pengujian Algoritma dilakukan dengan menggunakan software SPSS. Dari hasil penelitian yang telah dilakukan maka dapat membantu pihak BPDASHL untuk mempermudah dalam memprediksi pemesanan bibit dengan menggunakan Software SPSS.
\end{abstract}

Kata Kunci: Data Mining, Prediksi, Regresi Linear Berganda

Abstract

Data mining, often also called knowledge discovery in database (KDD), is an activity that includes collecting, using historical data to find order, patterns or relationships in large data sets. Outputs from data mining can be used to improve future decision making. Problems that often occur in BPDASHL are estimation problems such as weather, difficulties in planting, lack of labor, lack of experience in tree nurseries, and different soil conditions. Another problem that is found in agencies is that they do not have a system to predict estimated tree seedlings orders every year so that a method is needed, namely the Multiple Linear Regression Algorithm. So with this was made the Application of Data Mining To Predict Ordering Tree Seeds With Multiple Linear Regression. Multiple Linear Regression Algorithms which are methods that support estimating or predicting order targets for the coming period. Algorithm testing is done using SPSS software. From the results of the research that has been done, it can help BPDASHL to make it easier to predict the ordering of seeds using SPSS Software.

Keywords: Data Mining, Predictions, Multiple Linear Regression

\section{PENDAHULUAN}

Data Mining adalah serangkaian proses untuk menggali nilai tambah dari suatu kumpulan data berupa pengetahuan yang selama ini tidak diketahui secara manual.Data Mining dapat diterapkan pada berbagai bidang yang mempunyai sejumlah data,tetapi karena wilayah penelitian dengan sejarah yang belum lama,dan belum melewati masa 'remaja',maka data mining masih diperdebatkan posisi bidang pengetahuan yang memilikinya. Maka Daryl Pregibon menyatakan bahwa " Data Mining adalah campuran dari statistik,kecerdasan buatan,dan riset basis data " yang masih berkembang Data Mining mempunyai empat akar bidang ilmu yaitu Statistik,Kecerdasan Buatan ( Artificial Intelligence),Pengenalan Pola, dan Sistem Basis Data.

Prediksi adalah suatu proses memperkirakan secara sistematis tentang sesuatu yang paling mungkin terjadi di masa depan berdasarkan informasi masa lalu dan sekarang yang dimiliki, agar kesalahannya (selisih antara sesuatu yang terjadi dengan hasil perkiraan) dapat di perkecil. Prediksi tidak harus memberikan jawaban secara pasti kejadian yang akan terjadi, melainkan berusaha untuk mencari jawaban sedekat mungkin yang akan terjadi.

Kegiatan yang menjadi sumber dampak terhadap komponen lingkungan biologi adalah kegiatan penggunaan kawasan hutan. Penggunaan kawasan hutan terutama digunakan untuk fasilitas sumur dan penunjangnya. Dampak langsung terhadap hutan lindung dan cagar alam berupa pengurangan luas kawasan konservasi dan luas kawasan hutan lindung. Dampak tidak langsung atau akibat lanjutan dari penurunan luas kawasan konservasi adalah berubahnya struktur dan komposisi flora dan fauna, fungsi hidrologi dan kesuburan tanah. Dampak yang timbul walaupun tidak termasuk katagori dampak penting, upaya pengelolaan akan tetap dilakukan untuk meningkatkan kualitas lingkungan, kewajiban proses pinjam pakai dan meningkatkan citra perusahaan. Pemakaian lahan milik pemerintah, dalam hal ini Departemen Kehutanan, ada syarat-syarat yang wajib dipenuhi diantaranya adalah merevegetasi lahan-lahan yang terbuka (kritis) disekitar lokasi sumur dan pada lahan-lahan yang sudah tidak dipakai lagi. Beberapa pengelolaan telah dilaksanakan : optimalisasi pemakaian lahan (sistem cluster) dan revegetasi

Kantor Balai Pengelolaan Daerah Aliran Sungai Dan Hutan Lindung Wampu Sei Ular, sering disingkat sebagai BPDASHL WAMPU, adalah unit pelaksana teknis setingkat eselon III (atau eselon II untuk balai besar) di bawah Direktorat Jenderal Perlindungan Hutan dan Konservasi Alam Kementerian Kehutanan Republik Indonesia. Instansi ini di antaranya bertugas untuk mengelola kawasan-kawasan konservasi, khususnya hutan-hutan suaka alam (suaka margasatwa, cagar alam) dan taman wisata alam. Selain itu BPDAS WAMPUjuga bertanggung jawab mengawasi dan memantau peredaran tumbuhan dan satwa yang dilindungi di wilayahnya, termasuk pula memantau upaya-upaya 
penangkaran dan pemeliharaan tumbuhan dan satwa dilindungi oleh perorangan, perusahaan dan lembaga-lembaga konservasi terkait.Didalam dunia perdagangan, terutama dunia pemasaran pelaku pasar harus selalu cermat dalam memprediksi situasi pasar dan tentu saja dibutuhkan kecermatan dan ketelitian. Pada dasarnya masalah yang sering timbul dalam suatu perusahaan adalah kurangnya stock yang akan dijual(bisa dijual tetapi hanya terfokus pada bantuan), sehingga data yang didapatkan tidaklah terlalu banyak sehingga membuat para staf tidak perduli dengan target pemesanan dimasa yang akan datang.

Masalah yang sering terjadi di dalam suatu Instansi adalah masalah prediksi seperti cuaca,kesulitan dalam penanaman,kurangnya tenaga kerja,kurang pengalaman dalam pembibitan pohon,serta kondisi tanah yang berbeda-beda. Masalah lain yang terdapat dalam Instansi yaitu belum mempunyai sistem untuk memprediksi pemesanan bibit pohon setiap tahunnya sehingga diperlukan suatu metode yaitu Algoritma Regresi Linear Berganda.

Regresi Linear Berganda dapat diterapkan sebagai salah satu teknik menyelesaikan prediksi seperti penelitian oleh Ni Luh Putu Wulandari, Ni LuhAyu Kartika Yuniastari, dan GustiAyu Desi Saryanti dengan judul"Prediksi Jumlah Pelanggan Dan Persediaan Barang Menggunakan Metode Regresi Linear Beganda Pada Bali Orchid" menyatakan bahwa Untuk memudahkan dalam mengenali informasi yang tersimpan dalam data penjualan produk pada periode sebelumnya tersebut makan dibuat aplikasi yang dapat memprediksi masa depan dengan salah satu metode yang digunakan adalah regresi linear berganda[1]. Amrin "Data Mining DenganRegresi Linear Berganda Untuk Peramalan Tingkat Inflasi” menyatakan bahwa performa metode regresi linear bergand ayang dibentuk dari data training dan di validasi pada data testing memberikan tingkat akurasi prediksi yang cukup baik[2].

\section{METODE PENELITIAN}

\subsection{Data Mining}

Data mining, sering juga disebut knowledge discovery in database (KDD), adalah kegiatan yang meliputi pengumpulan, pemakaian data historis untuk menemukan keteraturan, pola atau hubungan dalam set data berukuran besar. Keluaran dari data mining bisa dipakai untuk memperbaikin pengambilan keputusan dimasa depan [3]. Dari defenisi-defenisi yang telah disampaikan, hal penting yang terkait dengan data mining adalah:

1. Data mining merupakan suatu proses otomatis terhadap data yang sudah ada.

2. Data yang akan diproses berupa data yang sangat besar

3. Tujuan data mining adalah mendapatkan hubungan atau pola yang akan mungkin memberikan indikasi yang bermanfaat.

\subsection{Prediksi}

Prediksi adalah suatu proses memperkirakan secara sistematis tentang sesuatu yang paling mungkin terjadi di masa depan berdasarkan informasi masa lalu dan sekarang yang dimiliki, agar kesalahannya (selisih antara sesuatu yang terjadi dengan hasil perkiraan) dapat di perkecil. Prediksi tidak harus memberikan jawaban secara pasti kejadian yang akan terjadi, melainkan berusaha untuk mencari jawaban sedekat mungkin yang akan terjadi[7].

\subsection{Algoritma Regresi Linear Berganda}

Regresi Linear Berganda adalah untuk meramalkan pengaruh dua variable predictor atau lebih terhadap satu variable kriterium untuk membuktikan ada atau tidaknya hubungan fungsional antara dua variabel bebas (X) atau lebih dengan sebuah variable terikat (Y)[9]. Bentuk persamaan garis regresi berganda adalah sebagai berikut :

Untuk 2 prediktor: $\mathrm{Y}=\mathrm{b}_{1}+\mathrm{b}_{2} \mathrm{X}_{1}+\mathrm{b}_{3} \mathrm{X}_{2}$

Untuk 3 prediktor: $Y=b_{1}+b_{2} X_{1}+b_{3} X_{2}+b_{4} X_{3}$

Untuk n prediktor: $Y=b_{1}+b_{2} X_{1}+b_{3} X_{2}+\ldots .+b_{n} X_{n}$

Langkah-langkah dalam analisis regresi berganda adalah sebagai berikut :

1. Buatlah tabel penolong untuk regresi berganda.

\begin{tabular}{|c|c|c|c|c|c|c|c|c|}
\hline $\mathrm{Y}$ & $\mathrm{X}_{1}$ & $\mathrm{X}_{2}$ & $\mathrm{YX}_{1}$ & $\mathrm{YX}_{2}$ & $\mathrm{X}_{1} \mathrm{X}_{2}$ & $\mathrm{X}^{2}{ }_{1}$ & $\mathrm{X}_{2}{ }_{2}$ & $\mathrm{Y}^{2}$ \\
\hline & & & & & & & & \\
\hline & & & & & & & & \\
\hline $\mathrm{Y}$ & $\mathrm{X}_{1}$ & $\mathrm{X}_{2}$ & $\mathrm{YX}_{1}$ & $\mathrm{YX}_{2}$ & $\mathrm{X}_{1} \mathrm{X}_{2}$ & $\mathrm{X}^{2}{ }_{1}$ & $\mathrm{X}_{2}{ }_{2}$ & $\mathrm{Y}^{2}$ \\
\hline
\end{tabular}

2. Memasukkan nilai-nilai itu ke dalam persamaan.

$\mathrm{Y}=\mathrm{b}_{1} \mathrm{n}+\mathrm{b}_{2} \Sigma \mathrm{X}_{1}+\mathrm{b}_{3} \Sigma \mathrm{X}_{2}$

$\mathrm{YX}_{1}=\mathrm{b}_{1} \Sigma \mathrm{X}_{1}+\mathrm{b}_{2} \Sigma \mathrm{X}_{1}^{2}+\mathrm{b}_{3} \Sigma \mathrm{X}_{1} \mathrm{X}_{2}$

$\mathrm{YX}_{2}=\mathrm{b}_{1} \Sigma \mathrm{X}_{2}+\mathrm{b}_{2} \Sigma \mathrm{X}_{1} \mathrm{X}_{2}+\mathrm{b}_{3} \Sigma \mathrm{X}_{2}^{2}$

Persamaan tersebut dapat dinyatakan dalam persamaan matriks berikut :

$\left[\begin{array}{lll}a_{11} & a_{12} & a_{13} \\ a_{21} & a_{22} & a_{23} \\ a_{31} & a_{32} & a_{33}\end{array}\right]\left[\begin{array}{l}b_{1} \\ b_{2} \\ b_{3}\end{array}\right]=\left[\begin{array}{l}h_{1} \\ h_{2} \\ h_{3}\end{array}\right]$

$\mathrm{A}$

$\mathrm{B}$

$\mathrm{H}$ 
Dengan :

\author{
A : Matriks (diketahui) \\ $\mathrm{H}$ : Vektor Kolom (diketahui) \\ B : Vektor Kolom (tidak diketahui)
}

Dari matriks diatas kita dapat mencari determinan $\mathrm{A}=\operatorname{det}(\mathrm{A})$

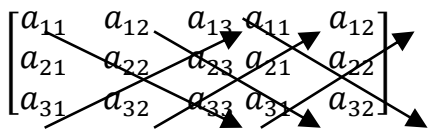

$\operatorname{Det}(\mathrm{A})=\mathrm{a}_{11} \mathrm{a}_{22} \mathrm{a}_{33}+\mathrm{a}_{12} \mathrm{a}_{23} \mathrm{a}_{31}+\mathrm{a}_{13} \mathrm{a}_{21} \mathrm{a}_{32}-\mathrm{a}_{31} \mathrm{a}_{22} \mathrm{a}_{13}-\mathrm{a}_{32} \mathrm{a}_{23} \mathrm{a}_{11}-\mathrm{a}_{33} \mathrm{a}_{21} \mathrm{a}_{12}$

Ada tiga persamaan dengan tiga variabel yang tidak diketahui nilainya yaitu $\mathrm{b}_{1}, \mathrm{~b}_{2}, \mathrm{~b}_{3}$ dan dapat dicari dengan rumus :

$\mathrm{b}_{1}=\frac{\operatorname{det}\left(A_{1}\right)}{\operatorname{det}(A)} ; \mathrm{b}_{2}=\frac{\operatorname{det}\left(A_{2}\right)}{\operatorname{det}(A)} ; \mathrm{b}_{3}=\frac{\operatorname{det}\left(A_{3}\right)}{\operatorname{det}(A)}$

Dimana :

$$
\mathrm{A}_{1}=\left[\begin{array}{lll}
h_{1} & a_{12} & a_{13} \\
h_{2} & a_{21} & a_{23} \\
h_{3} & a_{32} & a_{33}
\end{array}\right] \quad \mathrm{A}_{2}=\left[\begin{array}{lll}
a_{11} & h_{1} & a_{13} \\
a_{21} & h_{2} & a_{23} \\
a_{31} & h_{3} & a_{33}
\end{array}\right] \quad \mathrm{A}_{3}=\left[\begin{array}{lll}
a_{11} & a_{12} & h_{1} \\
a_{21} & a_{21} & h_{2} \\
a_{31} & a_{32} & h_{3}
\end{array}\right]
$$

3. Tuliskan persamaan garis regresi gandanya, dengan memasukkan nila-nilai $b_{1}, b_{2}, b_{3}$ ke dalam bentuk umum persamaan garis regresinya.

\title{
3. ANALISA DAN PEMBAHASAN
}

Analisa dalam penjualan dan pemesanan sangat perlu dilakukan di BPDASHL Wampu Sei Ular Medan.Analisa ini berguna untuk mendapatkan pokok-pokok permasalahan yang sebenarnya menjadi inti permasalahan yang sering terjadi di BPDASHL Wampu Sei Ular Medan. Dalam hal ini perlu melakukan analisa omset penjualan pertahun , ini bertujuan agar BPDASHL Wampu Sei Ular Medan dapat mengetahui langkah yang harus dilakukan dalam mendata persediaan bibit pohon pesanandi tahun yang akandatang ,dalam melakukan analisa pada penelitian ini digunakan data yang tercantum pada BPDASHL Wampu Sei Ular Medandari tahun 2015 sampai dengan tahun 2017.

Regresi Linear atau merupakan metode statistik yang bertujuan untuk membentuk sebuah model antara variabel dependen (Y) dengan variabel independen (X). Regresi Linear yang memiliki satu variabel bebas disebut dengan Regresi Linear Sederhana, sedangkan Regresi Berganda diperuntukkan apabila memiliki lebih dari satu vaariabel bebas. Regresi Linear menggunakan garis kecenderungan apabila pola data menunjukkan suatu kecenderunangan, baik berpola turun atau naik .Regresi Linear merupakan bagian regresi yang mencakup hubungan linear satu peubah tak bebas Y dengan satu peubah bebas X. Analisis regresi adalah metode untuk menentukan hubungan sebab-akibat antara satu variabel dengan variabelvariabel yang lain.

Variabel "penyebab" disebut dengan bermacam-macam istilah yaitu, variabel penjelas, variabel eksplanatorik, variabel independen, atau secara bebas, variabel X (karena seringkali digambarkan dalam grafik sebagai absis atau sumbu $\mathrm{X}$ ). Variabel terkena akibat dikenal sebagai variabel yang dipengaruhi, variabel dependen, variabel terikat, atau variabel Y. Kedua variabel ini dapat merupakan variabel acak (random), namun variabel yang dipengaruhi harus selalu variabel acak .

Bentuk umum Regresi Linear Berganda sebagai berikut:

$\hat{Y}=a+b_{1} X_{1}+b_{2} X_{2}+\cdots+b_{k} X_{k}$

Dimana:

$\hat{Y} \quad$ : nilai variabel Y hasil prediksi

$\mathrm{Y} \quad$ : variabel tak bebas

$\mathrm{X}$ : variabel bebas

a : konstanta regresi

b : koefisien regresi

Untuk mencari nilai konstanta a dan koefisien regresi b dapat dihitung dengan cara pendekatan matriks, persamaan normal (substitusi), dan metode kuadrat terkecil. Pada penelitian ini penulis menggunakan metode kuadrat terkecil, dari persamaan 2, maka dapat dicari nilai konstanta a dengan rumus

$a=\bar{Y}-b_{1} \bar{X}_{1}+b_{2} \bar{X}_{2}$

Untuk $\bar{Y}, \bar{X}_{1}, \bar{X}_{2}$ digunakan rumus:

$\bar{Y}=\frac{\sum Y}{n}$

$\bar{X}_{1}=\frac{\sum X_{1}}{n}$

$\bar{X}_{2}=\frac{\sum X_{2}}{n}$

b1 dan b2 dicari dengan persamaan:

$b_{1}=\frac{\left(\sum X_{2}^{2}\right)\left(\sum X_{1} Y\right)-\left(\sum X_{1} X_{2}\right)\left(\sum X_{2} Y\right)}{\left(\sum X_{1}^{2}\right)\left(\sum X_{2}^{2}\right)-\left(\sum X_{1} X_{2}\right)^{2}}$

$b_{2}=\frac{\left(\sum X_{1}^{2}\right)\left(\sum X_{2} Y\right)-\left(\sum X_{1} X_{2}\right)\left(\sum X_{1} Y\right)}{\left(\sum X_{1}^{2}\right)\left(\sum X_{2}^{2}\right)-\left(\sum X_{1} X_{2}\right)^{2}}$ 
Berikut ini adalah daftar pesanan bibit dapat dilihat pada tabel dibawah ini:

Tabel 1. Data Pemesanan Bibit

\begin{tabular}{cccc}
\hline No. & Bulan & Pelanggan & $\begin{array}{c}\text { Jumlah bibit } \\
\text { pohon }\end{array}$ \\
\hline 1. & Januari & 24 & 5.780 \\
2. & Februari & 10 & 8.600 \\
3. & Maret & 24 & 11.350 \\
4. & April & 23 & 10.350 \\
5. & Mei & 17 & 7.850 \\
6. & Juni & 7 & 11.420 \\
7. & July & - & - \\
8. & Agustus & 24 & 25.430 \\
9. & September & 10 & 9.100 \\
10. & Oktober & 24 & 37.850 \\
11. & November & 23 & 32.250 \\
12. & Desember & 17 & 23.450 \\
\hline
\end{tabular}

Tabel 2. Perhitungan Regresi Linear Berganda

\begin{tabular}{ccccccccc}
\hline $\mathrm{X}_{1}$ & $\mathrm{X}_{2}$ & $\mathrm{Y}$ & $\mathrm{X}_{1} \mathrm{Y}$ & $\mathrm{X}_{2} \mathrm{Y}$ & $\mathrm{X}_{1} \mathrm{X}_{2}$ & $\mathrm{X}_{1}{ }^{2}$ & $\mathrm{X}_{2}^{2}$ & $\mathrm{Y}^{2}$ \\
\hline 24 & 5.780 & 138.720 & 3.329 .280 & 80.180 .160 & 138.720 & 576 & 33.408 .400 & 19.243 .238 .400 \\
10 & 8.600 & 86.000 & 860.000 & 739.600 .000 & 86.000 & 100 & 73.960 .000 & 7.396 .000 .000 \\
24 & 11.350 & 272.400 & 6.537 .600 & 3.091 .740 .000 & 272.400 & 576 & 128.822 .500 & 74.201 .760 .000 \\
23 & 10.350 & 238.050 & 5.475 .150 & 2.463 .817 .500 & 238.050 & 529 & 107.122 .500 & 56.667 .802 .500 \\
17 & 7.850 & 133.450 & 2.268 .650 & 1.047 .582 .500 & 133.450 & 289 & 61.622 .500 & 17.808 .902 .500 \\
7 & 11.420 & 79.940 & 559.580 & 912.914 .800 & 79.940 & 49 & 130.416 .400 & 6.390 .403 .600 \\
- & - & - & - & - & - & - & - & - \\
24 & 25.430 & 610.320 & 14.647 .680 & 15.520 .437 .600 & 610.320 & 576 & 646.684 .900 & 372.490 .502 .400 \\
10 & 9.100 & 91.000 & 910.000 & 821.100 .000 & 91.000 & 100 & 82.810 .000 & 8.281 .000 .000 \\
24 & 37.850 & 908.400 & 21.801 .600 & 34.382 .940 .000 & 908.400 & 576 & 1.432 .622 .500 & 825.190 .560 .000 \\
23 & 32.250 & 741.750 & 17.060 .250 & 23.921 .437 .500 & 741.750 & 529 & 1.040 .062 .500 & 550.193 .062 .500 \\
17 & 23.450 & 398.650 & 6.777 .050 & 9.348 .342 .500 & 398.650 & 289 & 549.902 .500 & 158.921 .822 .500 \\
\hline
\end{tabular}

$\sum x_{1}=203$

$\sum x_{2}=183.430$

$\sum y=3.698 .680$

$\sum x_{1} x_{2}=37.236 .290$

$\sum x_{1} y=750.832 .040$

$\sum x_{2} y=678.448 .872 .400$

$\sum x_{1}^{2}=41.209$

$\sum x_{2}{ }^{2}=33.646 .564 .90$

$\sum y^{2}=13.680 .233 .742 .400$

Cari $\mathrm{A}=\left[\begin{array}{ccc}9 & 203 & 183.430 \\ 203 & 41.209 & 37.236 .290 \\ 183.430 & 37.236 .290 & 33.646 .564 .900\end{array}\right]\left[\begin{array}{l}b_{1} \\ b_{2} \\ b_{3}\end{array}\right]=\left[\begin{array}{c}3.698 .680 \\ 750.832 .040 \\ 678.448 .872 .400\end{array}\right]$

$\mathrm{A}_{1}=\left[\begin{array}{ccc}3.698 .680 & 203 & 183.430 \\ 750.832 .040 & 41.209 & 37.236 .290 \\ 678.448 .872 .400 & 37.236 .290 & 33.646 .564 .900\end{array}\right]$

Kemudian cari :

$\begin{aligned} A_{2} & =\left[\begin{array}{ccc}9 & 3.698 .680 & 183.430 \\ 203 & 750.832 .040 & 37.236 .290 \\ 183.430 & 678.448 .872 .400 & 33.646 .564 .900\end{array}\right] \\ A_{3} & =\left[\begin{array}{ccc}9 & 203 & 3.698 .680 \\ 203 & 41.209 & 750.832 .040 \\ 183.430 & 37.236 .290 & 678.448 .872 .400\end{array}\right]\end{aligned}$

$\operatorname{Det}(\mathrm{A})=(9 * 41209 * 33646564900)+(203 * 37236290 * 183430)+(183430 * 203 * 37236290)-(183430 * 41209 * 183430)-$ $(37236290 * 37236290 * 9)-(33646564900 * 203 * 203)=12476763690300000$ 


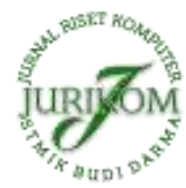

JURIKOM (Jurnal Riset Komputer), Vol. 7 No. 1, Februari 2020 e-ISSN 2715-7393 (Media Online), p-ISSN 2407-389X (Media Cetak) DOI 10.30865/jurikom.v7i1.1947 Hal 56-62

$\operatorname{Det}\left(\mathrm{A}_{1}\right)=(3.698 .680 * 41.209 * 33.646 .564 .900)+(203 * 31.236 .290 * 33.646 .564 .900)+(183.430 * 750.832 .040)-$ $(678.448 .872 .400 * 41.209 * 183.430) \quad-(37.236 .290 * 37.236 .290 * 3.698 .680) \quad-\quad(33.646 .564 .900 * 750.832 .040 * 203)$ $=10.043 .393 .207 .875 .588 .815 .800$

$\operatorname{Det}\left(\mathrm{A}_{2}\right)=(9 * 750.832 .040 * 33.646 .564 .900)+(3.698 .680 * 750.832 .040 * 183.430)+(183.430 * 203 * 678.448 .872 .400)-$ $(183.430 * 750.832 .040 * 183.430) \quad-\quad(678.448 .872 .400 * 37236290 * 9) \quad-\quad(33.646 .564 .900 * 203 * 3.698 .680)$ $=484.138 .231 .936 .932 .300 .000$

$\operatorname{Det}\left(\mathrm{A}_{3}\right)=(9 * 41209 * 678.448 .872 .400)+(203 * 750.832 .040 * 183.430)+(3.698 .680 * 203 * 37.236 .290)$

$(37.236 .290 * 750.832 .040 * 9)-(678.448 .872 .400 * 203 * 203)=555.897 .901 .582 .731 .600$

$\mathrm{B}_{1}=\frac{\operatorname{det}(A 1)}{\operatorname{det}(A)}=\frac{10.043 .393 \cdot 207.875 .588 .815 .800}{12476763690300000}=804.967$

$\mathrm{B}_{2}=\frac{\operatorname{det}(A 2)}{\operatorname{det}(A)}=\frac{484.138 .231 .936 .932 .300 .000}{12476763690300000}=38.803$

$\mathrm{B}_{3}=\frac{\operatorname{det}(A 3)}{\operatorname{det}(A)}=\frac{555.897 .901 .582 .731 .600}{12476763690300000}=44.554$

Maka $\mathrm{Y}=888.324$

\section{IMPLEMENTASI}

Implementasi sistem program ini mencakup spesifikasi kebutuhan perangkat keras (Hardware) dan spesifikasi perangkat lunak (Software). Implementasi diartikan sebagai pelaksanaan atau penerapan. Artinya yang dilaksanakan dan di terapkan adalah sistem yang telah dirancang atau di desain untuk kemudian dijalankan. Maka implementasi adalah suatu tindakan pelaksanaan dari sebuah rencana yang sudah disusun secara matang dan terperinci.

Implementasi sistem mempunyai tujuan yaitu sebagai berikut :

1. Membuat desain system selama melakukan penelitian Analisa.

2. Menguji serta mendokumentasi prosedur dan program yang dibutuhkan.

3. Menyelesaikan desain sistem yang sudah disetujui.

4. Memperhitungkan sistem yang sudah dibuat sesuai kebutuhan pengguna

Program ini di jalankan dengan menggunakan perangkat keras(hardware) yang mempunyai spesifikasi adalah sebagai berikut :

1. Processor Intel Core i3-3217U CPU @ $1.80 \mathrm{GHz} 1.70 \mathrm{GHz}$

2. Ram 2 GB

3. Operating System 64 bit

Untuk memulai menggunakan SPSS dengan memasukkan file yang ingin di proses.

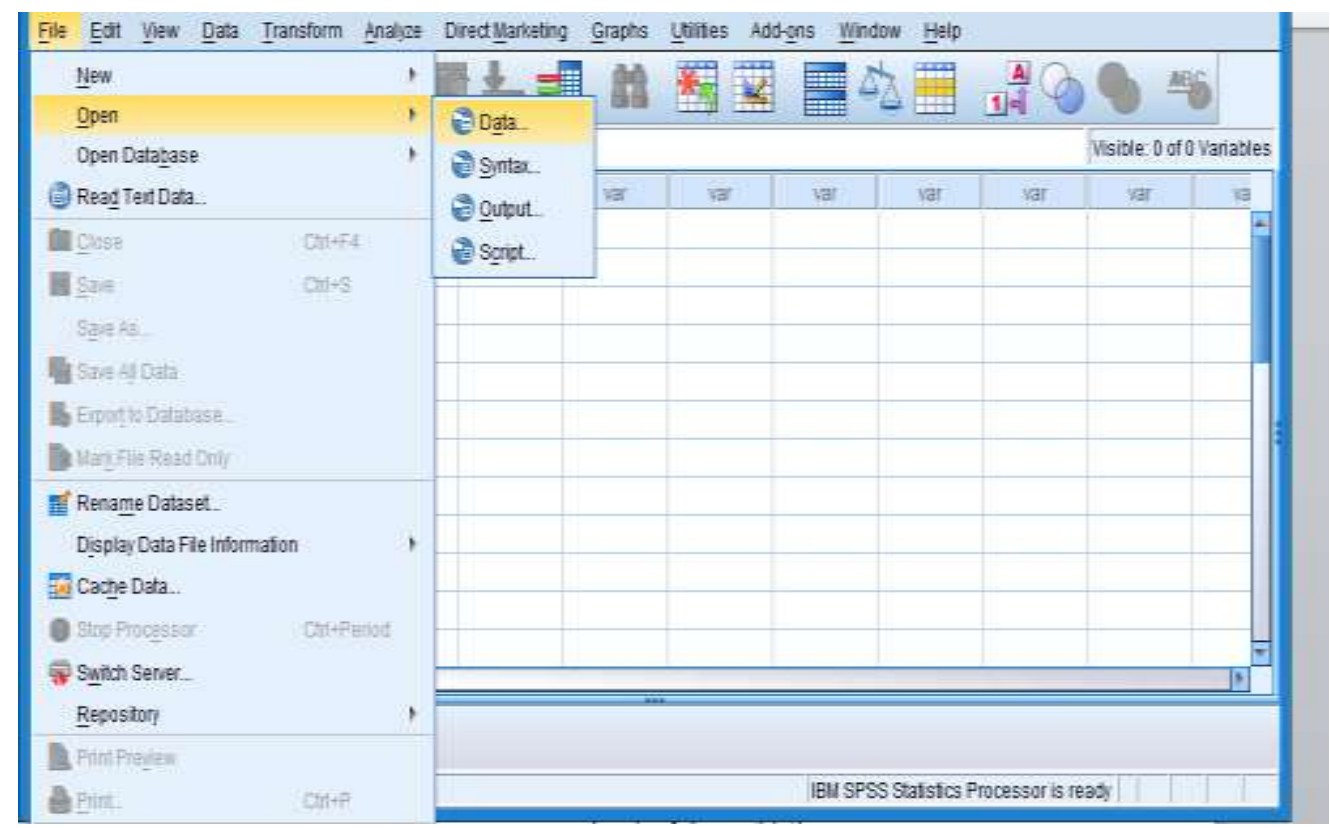

Gambar 1. Tampilan Data File Awal

Kemudian cari data pada folder yang ada pada dataset 


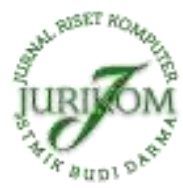

JURIKOM (Jurnal Riset Komputer), Vol. 7 No. 1, Februari 2020 e-ISSN 2715-7393 (Media Online), p-ISSN 2407-389X (Media Cetak) DOI 10.30865/jurikom.v7i1.1947

\begin{tabular}{|c|c|c|c|c|c|c|}
\hline Elle & Edit & view & Data & Iranisform & \multicolumn{2}{|r|}{ Analyze } \\
\hline \multirow[t]{2}{*}{$\Longrightarrow$} & $\ln x$ & $\Leftrightarrow$ & IDDE & tise- & -3 & 是是 \\
\hline & & \multicolumn{2}{|c|}{$\$ a \vee 1$} & $\$ \mathrm{a} v 2$ & & a v $\vee 3$ \\
\hline 1 & & \multicolumn{2}{|l|}{$\begin{array}{l}\text { Eulan } \\
\text { Jan }\end{array}$} & Pelangaan & & sin \\
\hline \multicolumn{2}{|l|}{$\frac{1}{2}$} & \multirow{2}{*}{\multicolumn{2}{|c|}{ rob }} & 5 & & 1440 \\
\hline \multicolumn{2}{|l|}{3} & & & $=$ & & - \\
\hline \multicolumn{2}{|l|}{4} & \multicolumn{2}{|l|}{ maret } & - & & - \\
\hline \multicolumn{2}{|l|}{$\frac{5}{6}$} & \multirow{2}{*}{\multicolumn{2}{|c|}{$\begin{array}{l}\text { aprit } \\
\text { mei }\end{array}$}} & - & & - \\
\hline \multirow{2}{*}{\multicolumn{2}{|c|}{$\frac{6}{7}$}} & & & - & & - \\
\hline & & \multicolumn{2}{|l|}{ juni } & - & & - \\
\hline \multicolumn{2}{|l|}{ a } & jull & & $=$ & & \multirow{2}{*}{25430} \\
\hline \multicolumn{2}{|l|}{9} & \multicolumn{2}{|l|}{ agu $=t u=$} & 17 & & \\
\hline \multicolumn{2}{|l|}{10} & \multicolumn{2}{|c|}{ ooptember } & G & & 9100 \\
\hline \multicolumn{2}{|l|}{$\begin{array}{l}11 \\
12\end{array}$} & \multirow{2}{*}{\multicolumn{2}{|c|}{$\begin{array}{l}\text { oktober } \\
\text { nov }\end{array}$}} & 22 & & 37750 \\
\hline \multirow{2}{*}{\multicolumn{2}{|c|}{$\begin{array}{l}12 \\
13\end{array}$}} & & & 13 & & 32250 \\
\hline & & \multirow{2}{*}{\multicolumn{2}{|c|}{ dos }} & 14 & & \multirow[t]{2}{*}{23450} \\
\hline 74 & & & & & & \\
\hline
\end{tabular}

Gambar 2. Dataset

Lalu tampilan selanjutnya seperti berikut ini, menjadidata editor

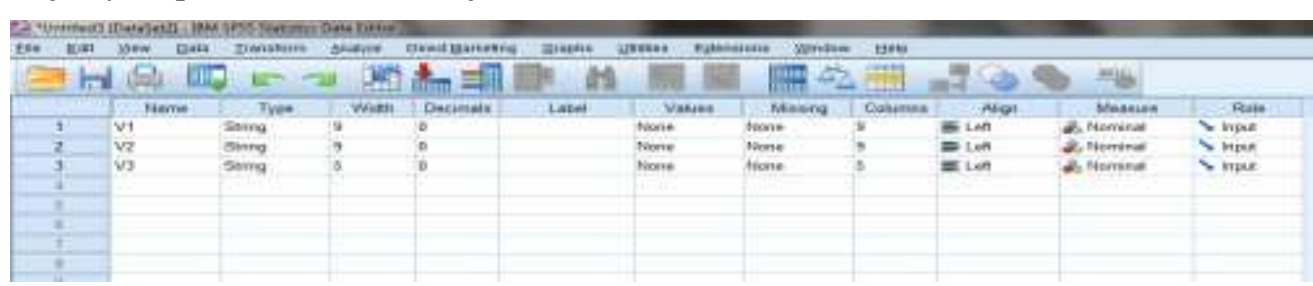

Gambar 3. Variabel View Data Pohon Mahoni

Pilih file yang diinginkan

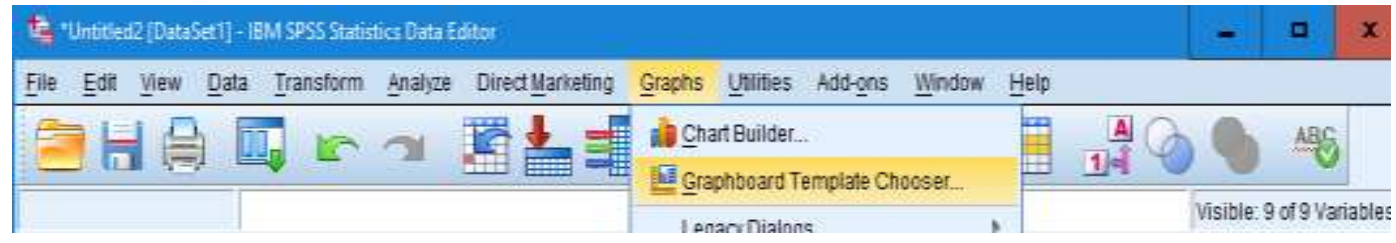

Gambar 4. Memilih Graph

Klik file yang ingin diolah, kemudian pilih “ $o k$ ”. Kemudianakan tampil tampilan seperti berikut:

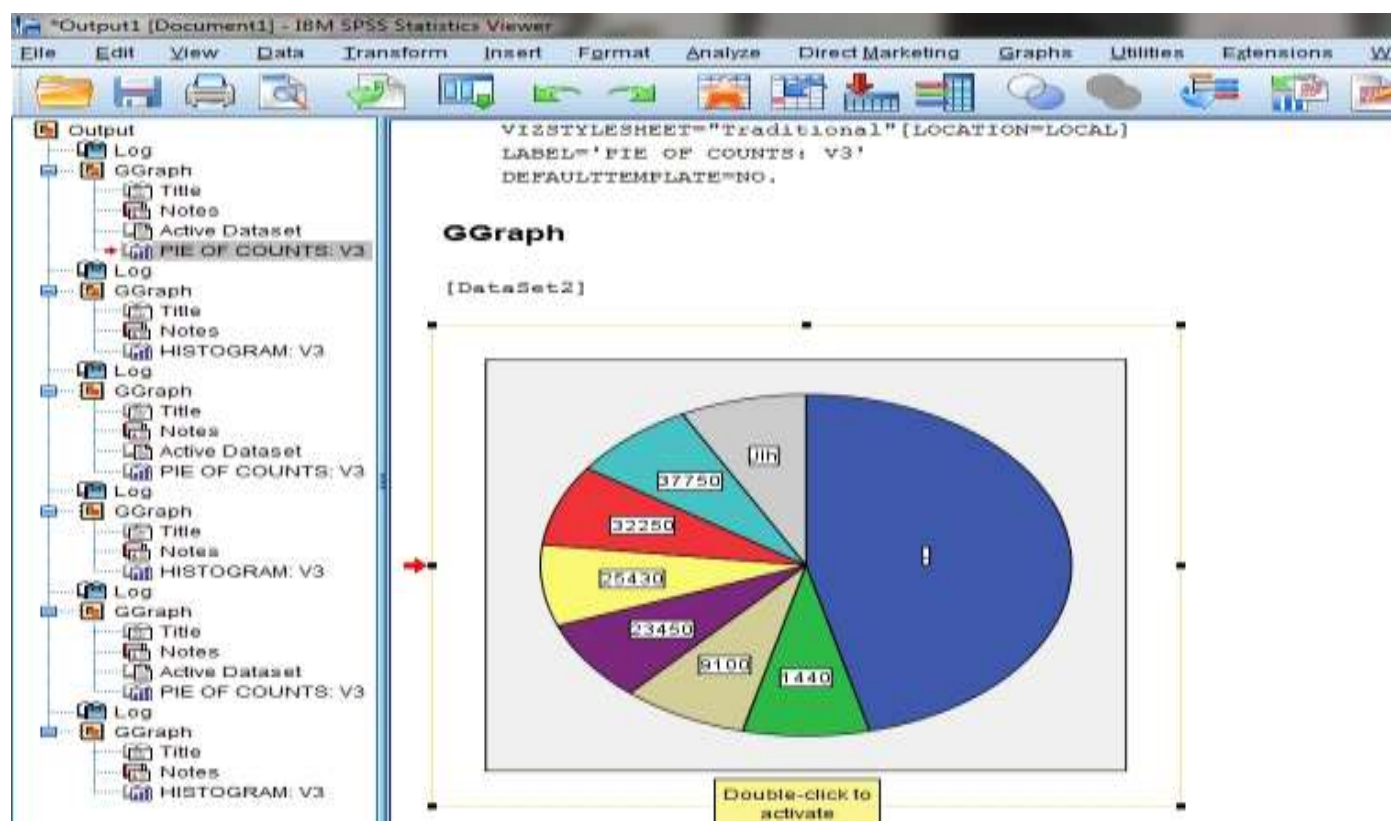

Gambar 5. Tampilan Dataset Dalam Bentuk GGraph Pohon Mahoni

Data hasil tabel dalam bentuk Histogram 


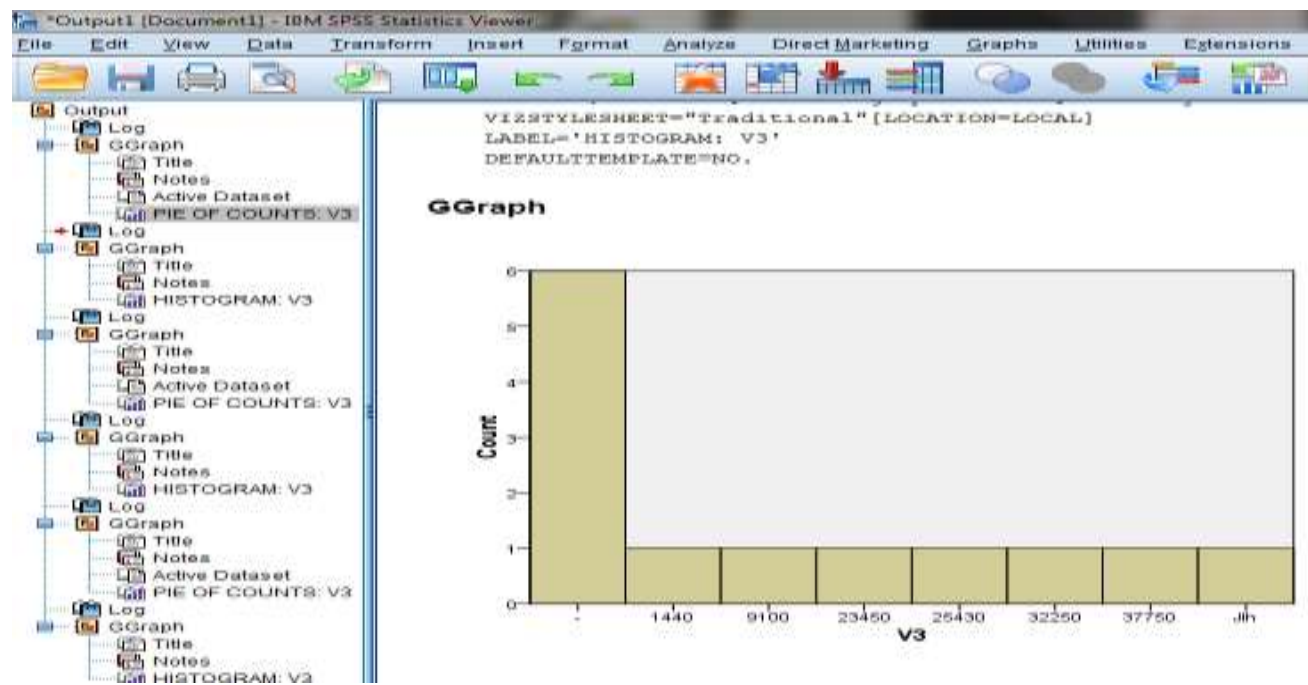

Gambar 6. Tampilan Hasil Dalam Bentuk Histogram Pohon Mahoni

\section{KESIMPULAN}

Berdasarkan penelitian yang telah dilakukan, maka penulis mengambil kesimpulan bahwa :

1. Memprediksi pemesanan bibit pohon pada BPDASHL dengan menggunakan data yang ada pada tahun-tahuns ebelumnya.

2. Algoritma yang digunakan untuk memprediksi pemesanan bibitpohon adalah Algoritma Regresi Linear Berganda.

3. Hasil Prediksi dalam pengujian SPSS adalah dalam bentuk tabel/grafik.

\section{REFERENCES}

[1] Ni Luh Putu Wulandari, Ni Luh A Kartika, I Gusti A Desi, "Prediksi Jumlah Pelanggan Dan Persediaan Barang Menggunakan Regresi Linear Berganda Pada Bali Orchid", 2015

[2] Amrin, "Data Mining Dengan Regresi Linear Berganda Untuk Peramalan Tingkat Inflasi”, 2016

[3] E. Buulolo, "Implementasi Algoritma Apriori Pada Sistem Persediaan Obat (Studi Kasus : Apotik Rumah Sakit Estomihi Medan)", 2013.

[4] F.A Hermawati, Data Mining, Yogyakarta : ANDI. 2013.

[5] Kusrini dan E.T. Luthfi, Algoritma Data Mining, Yogyakarta : Andi. 2009

[6] Budi Santosa, Data Mining, Teknik Pemanfaatan Data Untuk Keperluan Bisnis, Yogyakarta : Graha Ilmu.2007.

[7] Herdianto, "Prediksi Kerusakan Motor Induksi Menggunakan Metose Jaringan Saraf Tiruan Backpropagation", 2013.

[8] M.K. Lesilolo,"Pengujian Viabilitas Dan Vigor Benih Beberapa Jenis Tanaman Yang Beredar Di Pasaran Kota Ambon", Agrologia, Vol.2,pp.185,2013 .

[9] M.N Susanti, Statistika Deskriptif \& Induktif, Yogyakarta:Graha Ilmu. 2014.

[10] Wahana Komputer, Analisis Data Penelitian Dengan SPSS 22, Yogyakarta:ANDI.2014. 